\title{
The Institutional Dynamics Perspective of ICT for Health Initiatives in India
}

\author{
Rajesh Chandwani and Rahul De
}

As there has been a considerable investment in ICT for development (ICT4D) initiatives, policymakers, practitioners and academics are calling for a more comprehensive and meaningful assessment of the impact of such initiatives. While the impact assessment of ICT4D can be carried out from multiple perspectives, the institutional lens is opportune in examining the softer aspects of the impact such as the behavioural, cultural, and social dimensions. ICT4D interventions juxtapose two institutional logics, that of designer and of the users, which may or may not align with each other. The impact of the initiative depends on how the interplay between the logics unfolds. We exemplify the importance of institutional context in impact assessment of ICT4D initiatives by examining the interplay of the institutional logics in the healthcare system. We conceptualise the healthcare system in terms of the logic of choice, perpetuated by the ICT for health initiative, and the logic of care which is embedded in the core of the health system. The interaction between the two logics, in turn, determines how the intervention evolves. We arrive at a framework outlining the tensions arising from the interplay of the logic of choice and logic of care in the healthcare system when an ICT4D intervention is introduced.

R. Chandwani $(\bowtie)$

Personnel and Industrial Relations, Indian Institute of Management, Ahmedabad, India

e-mail: rajeshc@iimahd.ernet.in

R. De

Quantitative Methods and Information Systems, Indian Institute of Management, Bangalore, India e-mail: rahul@iimb.ernet.in 


\section{Introduction}

Information and communication technologies for development (ICT4D) projects are not implemented in a vacuum. Rather, ICT4D interventions can potentially influence the existing sociocultural-technical systems. In turn, the systems themselves can influence the evolution and adoption of the technology. Scholars have emphasised that human agency and technology have a bidirectional relationship and that evolution of technological intervention depends upon the interaction between human agency and technology (Orlikowski 1992). The interaction between human agency and technology is determined by institutional forces. "Institutions are the rules of the game in a society or, more formally, are the humanly devised constraints that shape human interaction" (North 1990: p. 3). The institutional perspective is opportune in highlighting the sociocultural-technical aspects of the ICT4D interventions. Introduction of an ICT4D initiative juxtaposes two different institutional systems, that of the project designers and implementers and of project users. The outcome of the project is then determined by the evolution of this institutional dualism (Heeks and Santos 2007).

Previous research has highlighted the importance of sociocultural factors as critical determinants for realisation of benefits from ICT usage (Chib et al. 2008; Miscione 2007; Walsham et al. 2007). The holistic assessment of impact of ICT4D initiatives, however, needs deliberation on how the ICT4D initiatives shape the existing institutional systems and how the institutional systems shape the technology usage and adaption. Scholars have called for research on the interaction of technology itself with specific aspects of social, economic, and cultural contexts (Walsham et al. 2007: p. 323). While most of the assessment frameworks used to measure the impact of ICT4D projects highlight the economic aspects of "impact" (such as in Arul Chib's introductory chapter and Kathleen Diga and Julian's May chapter later in this book), the institutional perspective is opportune in assessing the softer aspects of impact of ICT4D initiatives, such as the behavioural, cultural and social dimensions of the impact (Heeks and Molla 2009). Figure 1 below

Fig. 1 Relationship of technology and human behaviour (Adapted from Heeks and Molla 2009)

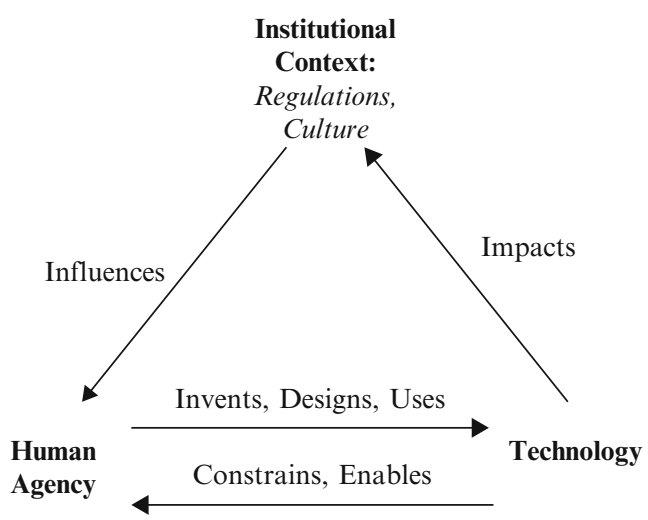


highlights the complex interaction between human agency, technology, and the institutional environment, both formal and informal, in shaping the impact of ICT4D interventions.

In this chapter, we focus on understanding how the implementation of an innovation in the form of an ICT4D initiative creates tension in the institutional dynamics and how these tensions affect the adaptation of the intervention. To highlight the institutional dualism (Heeks and Santos 2007), we refer to the "institutional logics" perspective. Institutional logics are the sociocultural norms, beliefs, and rules that shape the actors' cognition and behaviour; that is, how they make sense of the issues and how they act (Friedland and Alford 1991; Thornton 2004; Lounsbury 2007). Institutional logics provide a "stream of discourse that promulgates, however unwittingly, a set of assumptions" (Barley and Kunda 1992: p. 363). But institutional logics are seldom unidimensional and coherent. Rather, institutions, especially those which involve multiple and diverse stakeholders, such as healthcare systems, are characterised by coexistence of multiple, and sometimes conflicting, logics (Dunn and Jones 2010).

We exemplify the interplay of institutional dynamics by situating our discussion in the context of healthcare systems. The system of healthcare delivery can be conceptualised as an institution that is governed by logics that determine behaviour of stakeholders of health systems (Dunn and Jones 2010). Healthcare systems should be seen as institutions that are socio-technical systems with multiple stakeholders interacting with each other, such as the public and private healthcare organisations, political bodies, local community, regulatory bodies, financial institutions and so on (Arora 2010). The stakeholder behaviour and the socio-technical system are determined by the institutional context of healthcare. It is argued that ICT interventions can enable innovations in healthcare service delivery to extend the provision of affordable and quality healthcare for all (Sosa-Iudicissa et al. 1995). There has been substantial interest and investment in ICT interventions to enhance efficiency and effectiveness of healthcare delivery in developing countries. Facilitated by the increasing penetration of ICT, governments have made heavy investments in e-health initiatives (Blaya et al. 2010). E-health refers to the "use of information and communications technologies (ICT) in support of health and healthrelated fields, including healthcare services, health surveillance, health literature, and health education, knowledge and research" (World Health Organization 2005). The broad area of e-health includes several types of ICT for health initiatives such as m-health which involves use of mobile technologies, e.g. cell phones, SMS, etc. for strengthening healthcare delivery (Kahn et al. 2010), telemedicine which refers to use of telecommunication for connecting patients and doctors across geographies (Zolfo et al. 2011), Electronic Medical Records (EMR) which refers to creation and storage of health-related information of individuals in an electronic form that can be used by clinical and analytical purposes (Fraser et al. 2005), and so on. ICT interventions in the form of e-health initiatives can potentially influence the institutional system of healthcare delivery, and in turn the system can influence the evolution and adoption of the technology itself (Nicolini 2006). The posited 
Fig. 2 Interplay between ICT for health interventions and the institutional context

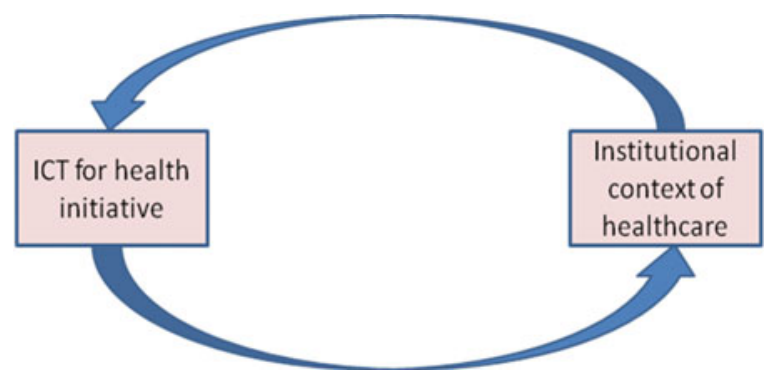

interplay between the ICT for health initiative and the existing institutional forces that shape healthcare delivery is represented in Fig. 2.

The literature on ICT for development, especially the dominant discourse on ICT for health initiatives, examines the economic dimension of interventions which highlights the efficiency-related aspects of the intervention (Blaya et al. 2010). There is a need to understand the adoption and evolution of ICT4D interventions from the sociocultural perspective and to explore how the system as an institution undergoes change, if any, from the intervention. The sociocultural and the institutional aspects of ICT interventions are more relevant for the effectiveness and sustainability of the intervention (Heeks and Molla 2009). In this paper, we attempt to address this gap by examining the evolution of ICT for health initiatives from the institutional logics perspective. ICT for health initiatives can be regarded as innovations that provide citizens with an alternative to their usual health-seeking avenues and that which can potentially alter the balance between conflicting logics prevalent in healthcare institutions where the interventions are attempted. The dominant rational view that ICT can act as a conduit for information transfer and hence knowledge transfer, making it possible for extending the access of medical knowledge for marginalised population and geographies, should be critically examined by investigating its effect on the basic assumptions and values that characterise the system (Arora 2010; Miscione 2007). In other words, innovations in healthcare can be understood in the backdrop of the logics that govern the healthcare system. Hence, we situate our discussion in the broad domain of logics in healthcare service institutions, specifically highlighting the trade-off between the logic of choice and logic of care (Mol 2008; van Schie and Seedhouse 1997).

The rest of the chapter is structured as follows. In the next section, we dwell on the concepts of logic of choice and logic of care in healthcare. Next, based on the extant literature, we highlight the emerging themes that arise from the interplay of the two logics in the healthcare domain. In the discussion and conclusion section, we arrive at a theoretical model explicating important dilemmas and tensions occurring due to institutional dynamics when an ICT initiative is introduced in the healthcare system. The chapter concludes by outlining the agendas for future research. 


\section{The Logic of Choice and Logic of Care}

The logic of choice in healthcare represents the libertarian conception of healthcare systems, emphasising that market-driven competition-enhancing policy measures can enhance the efficiency and effectiveness of the services provided to the patient (Fotaki 2010; van Schie and Seedhouse 1997). This assumption, however, does not take into account the complex relationships between the diverse stakeholders, the socio-economic, and the cultural norms which determine the aspect of "care" in the healthcare context. The logic of care refers to practices such as support, advice, encouragement and consolation, thus including both medical and social dimensions. The logic of care broadens the scope of healthcare by regarding patients as individuals being embedded in a social milieu rather than just diseased bodies and entails collaborative attempts to understand and attune diseased bodies and complex lives (Mol 2008). The logic of care takes into account the practices, "what they do", while the logic of choice refers to the possibilities presented to the stakeholders, "what are the choices available and what they choose to do" (Fotaki 2010; van Schie and Seedhouse 1997). The "they" in the above discussion could represent any stakeholder in the healthcare system. However, most of the studies, and rightly so, conceptualise the variables in terms of "they" as patients. For example, when a telemedicine programme is implemented in rural areas, the patient has a choice to consult a remote specialist on telemedicine or to continue seeking medical services from the local practitioners, usually practising complementary and alternative medicine (CAM). Thus, the technology drives the logic of choice. However, studies have shown that the patients continue to consult their local health service providers and come for telemedicine only if there is no relief from their primary recourse (See Miscione 2007). One of the important reasons for this behaviour is that the existing network of the health system provides the environment of care (Miscione 2007).

Health-seeking behaviour, and choice, is determined by the prevalent norms which in turn are determined by the logic of care. Franckel and Lalou (2009) studied the health-seeking behaviour for childhood malaria in rural Senegal. In the community, the child care-taking was a collective process involving mother, father, friends, and relatives, and treatment decision was a collective one. The collective management favoured home care and resulted in delayed recourse to health facilities. The above study highlights that logic of care is embedded in the relational and sociocultural and economic web. Indeed, it is argued that "care" is an integral and central part of healthcare systems and "choice" operates in a milieu of a broader "care".

It should be noted that the policy interventions and innovations in healthcare domain ultimately aim at improving the distal outcome variables such as decreased morbidity and mortality and enhanced quality of life. For example, the Millennium Development Goals (MDG), adopted by the UN General Assembly in 2000, targets poverty alleviation and improvement in health by 2015 as their ultimate distal outcome through international development programmes. The three MDGs directly 
relating to health aim at more proximal and measurable outcomes-reducing child mortality (MDG 4), improving maternal health (MDG 5), and controlling HIV, malaria, tuberculosis and other diseases (MDG 6). The inherent pluralism of logics in the healthcare domain highlights an important dilemma faced by the studies examining the impact of ICT for health interventions to identify a proximal variable that is relatively easy to assess (e.g. enhanced patient choice and incidence of malaria) or to examine a distal variable that is more difficult to measure, although it is more desirable (e.g. enhanced quality of life for inhabitants and that of care facilities). However, the above distinction is not very compartmental as it can be argued that the intermediate or proximal variables can be regarded as an end in themselves, for example, enhancing patient autonomy or patient choice. Further, there may be conflict between variables that can be categorised in a single domain, for example, increasing the lifespan of elderly patients (albeit with associated morbidities) may not align with the goal of enhancing the quality of life for the elderly. The policymakers' dilemma of emphasising proximal versus distal variables is discussed in the next section. Here, we would posit that in the context of ICT for health interventions, generally, the proximal variables such as patient choice, patient autonomy, patient centredness, and adoption of technology represent the logic of choice while the distal variables such as patient satisfaction, equity of care, and quality of life derive more from the care perspective.

The extant literature highlights the following aspects of the interaction between the logic of choice and the logic of care: (1) the complex relationships between the proximal and the distal variables, (2) the contextual nuances that affect how the interaction between the logics unfold, (3) the overemphasis on the "expert patient" in the logic of choice, and (4) the issues arising from the coexistence of a formal system of choice and a predominantly informal system emphasising the logic of care.

\section{Policymaker's Dilemma: Proximal or Distal Variables}

The assumption that intermediate variables such as patient autonomy relate to distal variables such as improved health outcomes should be understood in relation to the contextual and individual level variables. For example, if the patient is unable to make a choice, or for that matter if he or she does not wish to make a choice, or if the choice involves gathering and assimilating loads of information that is not readily available, emphasis on the patient autonomy and choice can be detrimental to long-term quality of life. Lee and Lin (2010) in their study on diabetic patients highlight that patient's autonomy is not directly related to favourable outcomes in the form of glycemic control. The relation is contingent upon various factors such as high decisional and high informational preferences. Further, there may be a conflict between choice and autonomy. Aune and Möller (2010), for example, demonstrated that women welcomed the option of getting an early ultrasound for detecting chromosomal anomalies in the fetus but did not want to take a decision 
regarding getting the ultrasound done themselves. Rather they preferred that their doctor should prescribe the investigation. Thus, they welcomed choice but not autonomy. Pilnick and Dingwall (2011) problematise patient centredness which entails patient autonomy as a universal good. They highlight that asymmetry is engrained in the institution of medicine and hence in the doctor-patient relationship and implementing autonomy that may be beneficial for some patients who prefer decision-making on their own. Dixon-Woods et al. (2006: p. 2742) similarly highlight how women provided "informed consent" for surgery though they were ambiguous about the decision as the decision-making process was "enmeshed in the hospital structure of tacit, socially imposed rules of conduct". "Informed decision-making", yet another concept emphasising patient autonomy and choice, thus, reinforced passivity rather than autonomy. Arguably, the complexities of the relationship between proximal and distal variables would be more pronounced in the context of healthcare for poor populations in developing countries, which is characterised by a high level of health illiteracy.

Isolated emphasis by policymakers on some intermediate outcomes, such as patient autonomy and choice, may negatively impact the universal values that a healthcare system envisages, for example, equity of care. The individualistic paradigm that forms the fundamental basis of patient choice and autonomy is diametrically opposite to the collectivistic and welfare paradigm that emphasises solidarity and equity of care (Fotaki 2010). Scholars call for de-emphasising the implicit incorporation of independence in autonomy, arguing for a relational understanding of autonomy while recognising its embeddedness in a web of relationships, and emphasise incorporating logic of care in doctor-patient relationships (Entwistle et al. 2010). To summarise, the logic of choice, while having merit, emphasises more on the proximal variables and may not resonate with the long-term distal outcomes. Thus, arguably, ICT for health interventions that solely emphasise choice without taking into consideration the distal variables determined by care is more likely to face resistance in their adoption.

\section{Contextual Aspects Can Affect the Logics}

The logic of care emphasises that contextual nuances should be taken into account in designing and modifying an intervention design to suit the context. It is the context that determines the environmental factors involved in the delivery of care. Hardon et al. (2011) problematise the mono-dimensional view, emphasising a patient's autonomy without taking contextual factors into consideration. They found that contrary to the choice logic, "provider-initiated tests" for HIV were more acceptable than voluntary testing in HIV centres in Uganda and Kenya. An in-depth analysis revealed that the sociocultural aspects of the society made voluntary testing, based on the principle of patient autonomy and choice, less attractive. The patients going for voluntary testing were considered to have a loose character, having "slept around", and hence were more comfortable when the tests were initiated by the 
healthcare provider. Further, the design of the interventions should pay attention to the existing health-seeking behaviour of the patients. Adoption of any intervention that undermines the existing channels or patterns of health-seeking behaviour is less likely. Chandler et al. (2011), for example, examined the introduction of a diagnostic test for malaria through a drugstore in Uganda. The intervention, however, did not result in expected increase in use of the test before taking treatment for malaria. The drug shops, which were an important source of healthcare services for community and were an important stakeholder in the established network of care and healthseeking, considered the diagnosis and treatment of malaria as synonymous. Thus the rational "choice" of having a diagnosis before the treatment was not deemed necessary in the existing network of care (i.e. drug shops). In both the examples above, the logic of care contrasted with the logic of choice.

Contextual factors shape the evolution of an intervention, determining whether the intervention will be adopted or not, or will be adopted fully or partially, or not at all, and the possible intended and unintended consequences (Orlikowski 1993). The dominant logics of healthcare systems may, thus, shape the introduction of interventions emphasising the logic of choice or logic of care. Robertson et al. (2011) explicate how the phenomenon of "shared decision-making" highlighted the role of a general practitioner as an expert rather than a partner in decisionmaking. "Shared decision-making" was used in minimising resistance to treatment solutions rather than in involving patients in their treatment decisions. Thus the characteristic of the context (i.e. power distance in doctor-patient interaction in healthcare) shaped the adoption and use of intervention (i.e. emphasis on shared decision-making) and, in fact, ossified the existing power distance between the provider and the receiver of service (Greenfield et al. 2012; Robertson et al. 2011). Kaufman et al. (2011), on the other hand, examine how a technology with indefinite or indeterminate effects found universal acceptance among the stakeholders. Their study demonstrates how the "technology imperative" drove the physicians, patients, relatives, and other stakeholders, such as manufacturers of the instruments and the insurance companies, to adopt novel technologies (e.g. implantable cardioverter defibrillator for elderly patients) that have ambiguous results in terms of choice as well as care (e.g. postponement of death but prolongs morbidity).

The existing health-seeking behaviour and the sociocultural and economic milieu in which the health-seeking behaviour is embedded form an integral part of the logic of care. Any intervention that supports the logic of choice should be designed in a manner that is supported by the contextual factors that determine the logic of care. Stoopendaal and Bal (2012) explicate how a "sociomaterial" setup was used in organisations for providing care to the elderly to enhance the quality of care provided by facilitating the choice of food for the inhabitants. The attempts for quality improvement recognised the situatedness of the phenomenon, thus providing alignment between the logic of care and logic of choice.

The above discussion highlights the importance of contextual dimensions such as the sociocultural, economic, and political aspects, which determine the logic of care. While ICT for health initiatives such as telemedicine or $\mathrm{m}$-health can be assumed to promote the logic of choice by making modern medical knowledge accessible to 
remote and rural populations, how the technology is adopted and how it evolves will be determined by the existing logic of care in which the intervention is embedded.

\section{Assumption of an "Expert Patient"}

Changing lifestyles and demographics have resulted in epidemics of chronic lifestyle-related illnesses such as diabetes and hypertension across the developed and the developing world. In case of such illnesses, where lifestyle modification forms an important aspect of treatment, it is often assumed that effective management involves converting a patient into an "expert patient" (Greenhalgh 2009). Driven by the logic of choice, the concept of the expert patient is based on the assumption that "teaching and training" of the patient in self-management will equip the patient with adequate knowledge and motivation to adhere to the prescribed treatment protocols (Mol 2008). The logic of choice emphasises that the patient is a rational individual who, once acquainted with the benefits of self-management, will indulge in actions that would maximise his or her wellbeing as an individual, that is, adherence to the treatment protocols (Gomersall et al. 2012). However, the studies emphasise that equipping patients with self-management may deprive them of the care environment and put the "blame" of any mismanagement onto the patients themselves (Mol 2008). Indeed, some patients consider self-management of diabetes at home as a demanding work (Hinder and Greenhalgh 2012). The success of self-management depends not only upon individual factors such as knowledge and motivation but also upon the family support and socio-economic contexts (Hinder and Greenhalgh 2012). The latter form a part of the care environment. Henwood et al. (2011) describe how a citizen patient, who is "nudged to adapt" the choice of healthy living habits in everyday life, negotiates between this logic of choice and the alternative logic of care in adopting health-promoting practices in their daily life. The sense-making that occurs in the process of negotiation is determined by the logic of care.

Patient expertise has three aspects: managing illness, managing everyday tasks with illness and enhancing the valuable sense of self. While the first aspect relates to logic of choice, the third aspect relates to logic of care, to feel secured and connected, and developing a sense of meaning and coherence (Aujoulat et al. 2012). Thus, the proper care of patients with chronic illnesses requires looking beyond the patient as an individual and laying isolated emphasis on making the patient "expert" in managing his or her illness (Greaney et al. 2012). The logic of care emphasises building more holistic models of care with the patient embedded in the family, society and the political contexts (Gomersall et al. 2012; Greenhalgh 2009).

Potentially, ICT for health interventions such as telemedicine, m-health, etc. can have a differential impact on patient empowerment and autonomy. An "expert" patient, who is thoroughly conversant with the use of technology and has the knowledge about his or her illness and management, may feel empowered by the use of ICT for health as it will result in "freeing" up of the abilities of the "expert" 
patient. However, the naïve patient, who has a limited knowledge of his illness and management or who is unable to utilise that knowledge effectively, may feel abandoned as the logic of care gets de-emphasised. A large majority of the poor population, which is the focus of most of the ICT for health interventions, has limited health literacy (Bhattacharyya et al. 2010) to fully utilise the capabilities emphasised by telemedicine. Further, ICT for health introduces a new dimension to the "expertise", technological expertise which refers to being conversant and comfortable with technology, thus complicating the issues arising from the assumption of an "expert" patient.

\section{Formal Versus Informal Systems}

An important aspect related to the logic of choice and logic of care is the interrelationship between the formal and informal systems that coexist within the healthcare context. ICT for health initiatives, largely driven by the governments or funding agencies, emphasises changes within the formal healthcare delivery system to enhance efficiency or effectiveness of the delivery process. For example, telemedicine initiatives in the developing countries, which seek to make "expert" specialist knowledge available to remote rural populations through the use of ICT, are usually implemented in the existing public health infrastructure in the remote areas. However, the informal systems in healthcare, such as the sociocultural aspects, play a crucial role in determining delivery and perception of "care". ICT for health initiatives, which provide an efficient alternative "choice" of healthcare delivery to the patients, generally highlight the formal aspects of the health system. In other words, ICT for health initiatives driven by the logic of choice largely emphasises the formal healthcare system. The logic of care, on the other hand, concerns the informal system of healthcare delivery. Empirical studies have shown that patients frequently resort to the informal systems that are driven predominantly by logic of care. For example, Stenner et al. (2011) find that patients preferred a nurse practitioner over a specialist in accessing primary care for chronic illnesses as they valued the "non-hurried" approach adopted by the nurses, the involvement of nurses in providing care and showing concern for the patients, their higher degree of approachability and length of the interactions, and better interpersonal skills, which raised the satisfaction level of patients' interaction with nurse practitioners. The above aspects highlighted the awareness about embeddedness and care in increasing patient satisfaction from the interaction. Similarly, studies have highlighted the preference of the informal over formal channels in case of doctors. Birk and Henriksen (2012) explicate that general practitioners, when referring a patient to a particular hospital, rely on the informal channels for gathering information about quality of care and services offered by the hospitals, for example, feedback from 
previously referred patients, recommendations from friends rather than the official data and figures available in the hospital databases. Chib et al. (2013a) highlight that rural doctors in China utilised both informal and formal networks to address their need for medical information, with informal guanxi networks compensating for the limitations of the formal healthcare information system.

Yet another important dimension highlighting the informal versus formal dilemma is the traditional versus biomedical systems of medicine which coexist in a healthcare system. Studies have shown that traditional systems of medicine form an integral part of health-seeking behaviour of the patients, especially in developing countries, and that these systems are central aspects of the logic of care (Miscione 2007; Sujatha 2007). Indeed, many educated patients and intelligent therapists resort to alternative medicine in spite of the limited scientific and statistical support for effectiveness of such therapies (Beyerstein 2001). Nissen and Manderson (2013) map the changing attitude of the healthcare systems in various countries across the world towards CAM (complementary and alternative medicine). CAM is heterogeneous with several societies considering specific CAM as legitimate, for example, Ayurveda in India and Chiropractic in Australia (Nissen and Manderson 2013). The coexistence of these systems affects the healthcare delivery processes. Sachs and Tomson (1992), for example, in their study on drug utilisation among doctors and patients in Sri Lanka illustrate how the sociocultural norms about Ayurveda influenced the doctor-patient interaction and drug usage. Policymakers and healthcare systems in several countries have started recognising the contribution of these systems of medicine in emphasising the logic of care, though the biomedical system proponents raise issues about the "lack of evidence base" in some of these systems. Telemedicine can complicate the already complex relationship between the traditional and biomedical systems of medicine interventions. CAM forms the usual recourse adopted by the patients, especially in the case of primary care in developing country contexts (Sujatha 2007; Shaikh et al. 2006). Telemedicine interventions that are largely restricted to the field of modern medicine emphasise biomedical conceptualisation of health, perpetuate the logic of choice by providing people with an alternative to their usual course of health-seeking in primary care, thus accentuating the conflict between the logic of care and logic of choice (cf. Merrell and Doarn 2012).

Further, the technology itself can be perceived differently by the doctors as well as patients. For example, while doctors are more likely to perceive telemedicine from a formal perspective (e.g. technology as conduit of knowledge), the patients may perceive it as an informal channel for communication (such as appearing on a television screen). The doctor can also invoke formality or informality in a telemedicine encounter by verbal and non-verbal cues. The differential perspectives potentially invoked by the doctors and patient can complicate the interplay between the choice and care logic. 


\section{Presence of Multiple Personnel in the Doctor-Patient Interaction}

In this discussion we focus on a specific type of ICT for health intervention, namely, telemedicine. In a doctor-patient interaction, the patient shares personal information related to health, illness and disease and about his or her personal life with the doctor to enable the doctor to reach a particular diagnosis. Maintaining the confidentiality of such personal information and a concern about privacy have been voiced and debated extensively in the healthcare literature (Chalmers and Muir 2003). The discussion on privacy and confidentiality in medical practice involves complex philosophical and conceptual issues (Rothstein 2010) and is out of the scope of this review. Here we highlight an important aspect of telemedicine which can potentially affect the perception of the patient about confidentiality and privacy issues, namely, presence of additional personnel in the telemedicine interaction and the concern about sharing the information with a person via electronic media rather than faceto-face (Miller 2001; Nicolini 2006).

The traditional doctor-patient interaction in a personal visit usually occurs on a one-to-one basis between the doctor and the patient. In tele-visits (telemedicine interactions), however, there are multiple personnel such as technicians, coordinators, and IT assistants who are listening to the interaction, though not directly involved in the medical aspects of the consultation. Involvement of multiple personnel jeopardises the perception of confidentiality and privacy in such consultations (Stanberry 2001). Further, as Labov (1972) highlighted, the phenomenon of the observer's paradox, that is, the difference in behaviour from the usual norms occurring as a result of perception of being observed, can alter the dynamics of doctor-patient interaction. Previous researchers have highlighted other issues arising from one to many medical consultations such as loss of patient centredness in the consultation process (Bristowe and Patrick 2012) and a perception of disempowerment and loss of self-autonomy in the patients (Rees et al. 2007; Maseide 2006). Pilnick et al. (2009) map the studies on conversational analysis of doctor-patient interactions, highlighting the need to look beyond dyadic interactions between doctor and patient to include other health professionals as well and multiparty interactions (see also Rothstein 2010).

Thus it can be conceptualised that the traditional personal visit supports the patient's perception of privacy and confidentiality, thus emphasising the logic of care. Telemedicine consultations, on the other hand, are characterised by the patient's apprehension about sharing his or her personal information with a "remote" consultation over an electronic media and in the presence of multiple personnel, thus jeopardising the logic of care. Scholars have called for further research exploring the dynamics of privacy issues in telemedicine consultations (Fleming et al. 2009). Confidentiality issues have been highlighted in other ICT for health interventions also such as m-health. Chib et al. (2013b) examine the Ugandan HIV/AIDS SMS campaign and highlighted complex gender issues involved in the 
implementation of the programme. They found that as the primary user of the mobile phone was a male, it jeopardised the freedom and confidence of female patients to share private information over the SMS.

\section{Discussion and Conclusion}

Most of the 2.6 billion people living under USD 2 a day, largely in low- and middle-income countries, have limited access to health services due to limited economic resources, residence in remote or rural areas, and lack of health literacy (Bhattacharyya et al. 2010). This results in significant lacunae in healthcare delivery among a population that, in fact, requires affordable, accessible, and quality healthcare services. In India, for example, $75 \%$ of healthcare facilities (i.e. infrastructure and manpower) is concentrated in urban areas which accounts for only $27 \%$ of the population of the nation. The lack of manpower is mainly at the specialists' level with about half of the posts for surgeons, gynaecologists, paediatricians and physicians lying vacant in rural areas (Bhandari and Dutta 2007). ICT interventions, such as m-health and telemedicine, acting as a conduit for information offer a promise to bridge the knowledge gap between the "haves" and the "have-nots" between the urban and rural areas. However, isolated emphasis on the economic aspects of ICT interventions assumes a linear relationship between knowledge-information transmission and development, which usually underlies such endeavours. ICT interventions considerably alter the institutional dynamics of the existing healthcare system, which is embedded in the sociocultural-political environment. Impact assessment of such interventions would be incomplete without considering the softer dimensions of the "impact", such as the changes in behavioural and cultural aspect of the community, and the effect on the existing institutional systems. Indeed, the longevity of the change process depends upon the softer dimensions such as depth (deep and consequential change in the processes), sustainability (the programme should result in policy implications so that the change is sustained over time), spread (involve the diffusion of underlying beliefs, norms and values that form the bases of the programme) and shift in the reform ownership (the shift of knowledge, ownership and decision-making from external sources who initiated the project to internal people who are the part of the process) (Coburn 2003: p. 4). Scholars have called for incorporating the cultural and institutional dimensions of the context in the frameworks for assessing the impact of ICT4D intervention (Heeks and Molla 2009). We began with the broad theoretical framework (Fig. 2), emphasising that the ICT for development initiatives, potentially, can affect and are affected by the institutional context.

We attempt to exemplify the importance of institutional context in impact assessment of ICT4D initiatives by examining the interplay of the institutional logic of choice and logic of care in the healthcare system. When an innovative intervention in the form of ICT for health initiative such as telemedicine or m-health is introduced in the system, it juxtaposes the two institutional logics. The evolution 
of the interaction between the two logics, in turn, determines how the intervention unfolds. The tensions between the key conceptual aspects arise when the logic of choice and logic of care are juxtaposed as a result of ICT4D intervention. Figure 3 details the tensions arising from the interplay of the logic of choice and logic of care in healthcare system when an ICT4D intervention is introduced. We identified four different aspects of the tension between the logics of choice and logic of care, namely, (1) between the proximal and distal variables, (2) an "expert patient" and

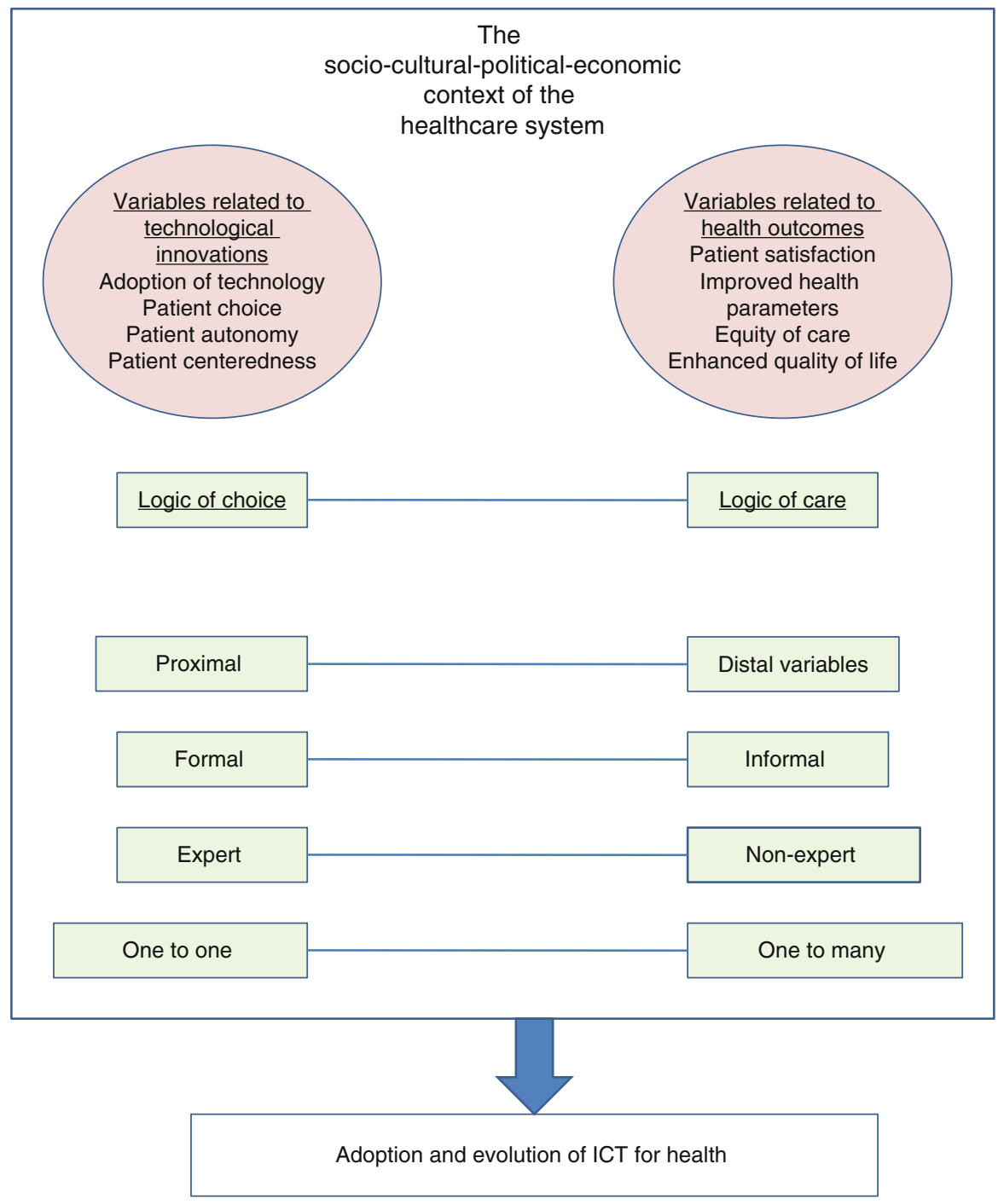

Fig. 3 The tension between logic of choice and logic of care determining the adoption and evolution of ICT for health initiatives 
a "naïve patient", (3) formal and informal systems and (4) presence of multiple personnel in the doctor-patient interaction and one-to-one interaction, respectively. These "tensions" form the two ends of a continuum, and it is the interplay between these factors that determine the adoption and evolution of the ICT for health initiative in the community.

The above analysis reiterates the complex sociocultural context of the healthcare system that determines the care environment. An ICT4D intervention, such as $\mathrm{m}$-health or telemedicine, enables the patient to access the healthcare system through ICT or through the conventional face-to-face encounters. The intervention, thus, enhances the "choice" to the patient to seek access to healthcare. However, the innovative interventions that are driven by the logic of choice and patient centredness are embedded in the context of the logic of care and hence any intervention results in an interaction between the two logics. The adoption of the intervention will be determined by the interplay between the two logics. As "care" forms the core of a healthcare system, we posit that the intervention will be adopted, often in a modified form, so as to facilitate an overlap between the two logics, that of care and of choice. In other words, adoption of the "choice" and the entailing improvements in the system are determined by the alignment of the programme with the broader environment of the "care". The above analysis has an implication for scholars engaged in assessment of the "impact" of ICT4D initiatives as well as the designers and the implementers of the initiative. The programme designers of one of the m-health initiatives in India (http://e-mamta.gujarat.gov.in/), for example, recognised that in rural areas, the community health worker form an important aspect of primary care-seeking. The programme aimed at early detection and treatment of high-risk pregnancies in rural parts of the state of Gujarat, India. The programme designed involved collecting and reporting health information from the patients through the use of SMS in the local vernacular language (in Gujarati). The health workers collected simple information such as vital signs, vaccination status and so on from the patient and sent the information to the State Rural Health Mission, which then set alerts for mother and infants for regular medications and vaccination. The above example highlights that successful implementation of ICT for health initiative emphasises the overlap between the logic of choice (m-health) and logic of care (involvement of community health worker).

The framework highlighting the institutional dualism between logic of choice and logic of care in healthcare reiterates the importance of developing an indepth understanding of the context and the existing institutional systems. The analysis based on the framework would not only enable a context-sensitive design of the innovation but also outline a roadmap for assessment of an ICT for health intervention for policymakers.

While the above framework pertains to the context of healthcare system, we posit that the core concepts of the framework, that is, the tensions arising from diverse institutional systems being juxtaposed, are generalisable to a broader domain of ICT4D interventions. Scholars have highlighted the issue of "institutional dualism" that ensues when an ICT4D intervention is introduced in an existing system (Heeks and Santos 2007). 


\section{Directions for Future Research}

The above analysis reveals several potential areas for future research for examining how the logic of care and logic of choice interplay with each other and the role of ICT in the evolving dynamics. The context of ICT interventions in healthcare such as telemedicine, Web 2.0, HIS systems, electronic medical records, m-health and so on provides fertile areas to investigate the changing logics of the institution of healthcare. For example, studies have shown that Internet can not only enhance clinical and material care which enables managing diseases more effectively but also can act as spaces where people can care for themselves and others (Atkinson and Ayers 2010). As the use of social media becomes ubiquitous and the Internet alters the semantics of "friendship" and "relationships", future research is required to determine the role of the Internet in providing care. Further, as patients and doctors increasingly use Web 2.0 and mobile technologies to gather and share information (see, e.g. Chib 2010), several issues need to be investigated such as the pattern of knowledge sharing and the evolution of the relationships among the healthcare professionals and between healthcare professionals and the patients. Eriksson and Salzmann-Erikson (2013), for example, highlight how the cyber nurses project their expertise on the Web in medical discussion forums. Researchers also need to investigate the gender issues and other sociocultural suspects of the use of ICT in healthcare. Another interesting area of research would be to examine how the doctors and patients make sense of a virtual doctor-patient interaction. For example, tacit clues like non-verbal communications, body language, etc. play an important role in determining the effectiveness of doctor-patient interaction (Henry et al. 2011). To enhance the effectiveness of the virtual tele-consultation, it is essential to examine "how the doctors and patients perceive non-verbal and tacit communication in a virtual interaction" and how this perception affects the quality of the interaction. Further, while we have examined the ICT for health initiatives from the institutional logics perspective, further research from diverse perspectives, such as behavioural sciences and communication studies, will provide a more holistic understanding of the phenomenon.

Open Access This chapter is distributed under the terms of the Creative Commons Attribution Noncommercial License, which permits any noncommercial use, distribution, and reproduction in any medium, provided the original author(s) and source are credited.

\section{References}

Arora, P. (2010). Digital gods: The making of a medical fact for rural diagnostic software. The Information Society, 26(1), 70-79.

Atkinson, S., \& Ayers, A. (2010). The potential of the internet for alternative caring practices for health. Anthropology and Medicine, 17(1), 75-86.

Aujoulat, I., Young, B., \& Salmon, P. (2012). The psychological processes involved in patient empowerment. Orphanet Journal of Rare Diseases, 7(Suppl 2), A31. 
Aune, I., \& Möller, A. (2010). 'I want a choice, but I don't want to decide'-A qualitative study of pregnant women's experiences regarding early ultrasound risk assessment for chromosomal anomalies. Midwifery, 28(1), 14-23.

Barley, S. R., \& Kunda, G. (1992). Design and devotion: Surges of rational and normative ideologies of control in managerial discourse. Administrative Science Quarterly, 37, 363-399.

Beyerstein, B. L. (2001). Alternative medicine and common errors of reasoning. Academic Medicine, 76(3), 230-237.

Bhandari, L., \& Dutta, S. (2007). Health infrastructure in rural India (India infrastructure report). New Delhi: Oxford University Press.

Bhattacharyya, O., Khor, S., McGahan, A., Dunne, D., Daar, A. S., \& Singer, P. A. (2010). Innovative health service delivery models in low and middle income countries - What can we learn from the private sector. Health Research Policy and Systems, 8(1), 24.

Birk, H. O., \& Henriksen, L. O. (2012). Which factors decided general practitioners' choice of hospital on behalf of their patients in an area with free choice of public hospital? A questionnaire study. BMC Health Services Research, 12(1), 126.

Blaya, J. A., Fraser, H. S., \& Holt, B. (2010). E-health technologies show promise in developing countries. Health Affairs, 29(2), 244-251.

Bristowe, K., \& Patrick, P. L. (2012). Do too many cooks spoil the broth? The effect of observers on doctor-patient interaction. Medical Education, 46(8), 785-794.

Chalmers, J., \& Muir, R. (2003). Patient privacy and confidentiality: The debate goes on; the issues are complex, but a consensus is emerging. British Medical Journal, 326(7392), 725.

Chandler, C. I., Hall-Clifford, R., Asaph, T., Pascal, M., Clarke, S., \& Mbonye, A. K. (2011). Introducing malaria rapid diagnostic tests at registered drug shops in Uganda: Limitations of diagnostic testing in the reality of diagnosis. Social Science \& Medicine, 72(6), 937-944.

Chib, A. (2010). The Aceh Besar midwives with mobile phones project: Design and evaluation perspectives using the information and communication technologies for healthcare development model. Journal of Computer-Mediated Communication, 15(3), 500-525.

Chib, A., Lwin, M. O., Ang, J., Lin, H., \& Santoso, F. (2008). Midwives and mobiles: Improving healthcare communications via mobile phones in Aceh Besar, Indonesia. Asian Journal of Communication, 18(4), 348-364.

Chib, A., Phuong, T. K., Si, C. W., \& Hway, N. S. (2013a). Enabling informal digital guanxi for rural doctors in Shaanxi, China. Chinese Journal of Communication, 6(1), 62-80.

Chib, A., Wilkin, H., \& Hoefman, B. (2013b). Vulnerabilities in mHealth implementation: A Ugandan HIV/AIDS SMS campaign. Global Health Promotion, 20 (1 suppl), 26-32.

Coburn, C. E. (2003). Rethinking scale: Moving beyond numbers to deep and lasting change. Educational Researcher, 32(6), 3-12.

Dixon-Woods, M., Williams, S. J., Jackson, C. J., Akkad, A., Kenyon, S., \& Habiba, M. (2006). Why do women consent to surgery, even when they do not want to? An interactionist and Bourdieusian analysis. Social Science \& Medicine, 62(11), 2742-2753.

Dunn, M. B., \& Jones, C. (2010). Institutional logics and institutional pluralism: The contestation of care and science logics in medical education, 1967-2005. Administrative Science Quarterly, 55(1), 114-149.

Entwistle, V. A., Carter, S. M., Cribb, A., \& McCaffery, K. (2010). Supporting patient autonomy: The importance of clinician-patient relationships. Journal of General Internal Medicine, 25(7), 741-745.

Eriksson, H., \& Salzmann-Erikson, M. (2013). Cyber nursing: Health 'experts' approaches in the post-modern era of virtual encounters. International Journal of Nursing Studies, 50(3), 335-344.

Fleming, D. A., Edison, K. E., \& Pak, H. (2009). Telehealth ethics. Journal of Telemedicine and e-Health, 15(8), 797-803.

Fotaki, M. (2010). Patient choice and equity in the British National Health Service: Towards developing an alternative framework. Sociology of Health \& Illness, 32(6), 898-913.

Franckel, A., \& Lalou, R. (2009). Health-seeking behaviour for childhood malaria: Household dynamics in rural Senegal. Journal of Biosocial Science, 41(1), 1. 
Fraser, H. S., Biondich, P., Moodley, D., Choi, S., Mamlin, B. W., \& Szolovits, P. (2005). Implementing electronic medical record systems in developing countries. Informatics in Primary Care, 13(2), 83-96.

Friedland, R., \& Alford, R. R. (1991). Bringing society back in: Symbols, practices and institutional contradictions. In W. W. Powell \& P. J. DiMaggio (Eds.), The new institutionalism in organizational analysis (pp. 232-263). Chicago: University of Chicago Press.

Gomersall, T., Madill, A., \& Summers, L. K. (2012). Getting one's thoughts straight: A dialogical analysis of women's accounts of poorly controlled type 2 diabetes. Psychology \& Health, 27(3), 378-393.

Greaney, A. M., O’Mathúna, D. P., \& Scott, P. A. (2012). Patient autonomy and choice in healthcare: Self-testing devices as a case in point. Medicine, Health Care, and Philosophy, 15, 383-395.

Greenfield, G., Pliskin, J. S., Feder-Bubis, P., Wientroub, S., \& Davidovitch, N. (2012). Patientphysician relationships in second opinion encounters - The physicians' perspective. Social Science \& Medicine, 75(7), 1202-1212.

Greenhalgh, T. (2009). Chronic illness: Beyond the expert patient. British Medical Journal, 338(7695), 629-631.

Hardon, A., Kageha, E., Kinsman, J., Kyaddondo, D., Wanyenze, R., \& Obermeyer, C. M. (2011). Dynamics of care, situations of choice: HIV tests in times of ART. Medical Anthropology, 30(2), 183-201.

Heeks, R. B., \& Molla, A. (2009). Impact assessment of ICT-for-development projects: A compendium of approaches (Development Informatics Working Paper No. 36). University of Manchester, Manchester. Retrieved from http://www.sed.manchester.ac.uk/idpm/research/ publications/wp/di/di_wp36.htm. Accessed 12 June 2013.

Heeks, R. B., \& Santos, R. (2007). Enforcing adoption of public sector innovations: Principals, agents and institutional dualism in a case of e-Government. Unpublished manuscript, Development Informatics Group, IDPM, University of Manchester, Manchester.

Henry, S. G., Forman, J. H., \& Fetters, M. D. (2011). 'How do you know what Aunt Martha looks like?'A video elicitation study exploring tacit clues in doctor-patient interactions. Journal of Evaluation in Clinical Practice, 17(5), 933-939.

Henwood, F., Harris, R., \& Spoel, P. (2011). Informing health? Negotiating the logics of choice and care in everyday practices of 'healthy living'. Social Science \& Medicine, 72(12), 2026-2032.

Hinder, S., \& Greenhalgh, T. (2012). 'This does my head in'. Ethnographic study of selfmanagement by people with diabetes. BMC Health Services Research, 12(1), 83.

Kahn, J. G., Yang, J. S., \& Kahn, J. S. (2010). 'Mobile' health needs and opportunities in developing countries. Health Affairs, 29(2), 252-258.

Kaufman, S. R., Mueller, P. S., Ottenberg, A. L., \& Koenig, B. A. (2011). Ironic technology: Old age and the implantable cardioverter defibrillator in US health care. Social Science \& Medicine (1982), $72(1), 6$.

Labov, W. (1972). Sociolinguistic patterns (Vol. 4). Philadelphia: University of Pennsylvania Press.

Lee, Y. Y., \& Lin, J. L. (2010). Do patient autonomy preferences matter? Linking patient-centered care to patient-physician relationships and health outcomes. Social Science \& Medicine, 71(10), 1811-1818.

Lounsbury, M. (2007). A tale of two cities: Competing logics and practice variation in the professionalizing of mutual funds. Academy of Management Journal, 50(2), 289-307.

Maseide, P. (2006). Body talk: The multiple dimensions of medical discourse. COMET conference, Cardiff, 29 June-1 July 2006.

Merrell, R. C., \& Doarn, C. R. (2012). Real time, old time. Journal of Telemedicine and e-Health, $18(4), 251-252$.

Miller, E. A. (2001). Telemedicine and doctor-patient communication: An analytical survey of the literature. Journal of Telemedicine and Telecare, 7(1), 1-17.

Miscione, G. (2007). Telemedicine in the Upper Amazon: Interplay with local health care practices. MIS Quarterly, 31, 403-425. 
Mol, A. (2008). The logic of care: Health and the problem of patient choice. London/New York: Routledge.

Nicolini, D. (2006). The work to make telemedicine work: A social and articulative view. Social Science \& Medicine, 62(11), 2754-2767.

Nissen, N., \& Manderson, L. (2013). Researching alternative and complementary therapies: Mapping the field. Medical Anthropology, 32(1), 1-7.

North, D. C. (1990). Institutions, institutional change and economic performance. Cambridge/New York: Cambridge University Press.

Orlikowski, W. J. (1992). The duality of technology: Rethinking the concept of technology in organizations. Organization Science, 3(3), 398-427.

Orlikowski, W. J. (1993). CASE tools as organizational change: Investigating incremental and radical changes in systems development. MIS Quarterly, 17(3), 309-340.

Pilnick, A., \& Dingwall, R. (2011). On the remarkable persistence of asymmetry in doctor/patient interaction: A critical review. Social Science \& Medicine, 72(8), 1374-1382.

Pilnick, A., Hindmarsh, J., \& Gill, V. T. (2009). Beyond 'doctor and patient': Developments in the study of healthcare interactions. Sociology of Health \& Illness, 31(6), 787-802.

Rees, C. E., Knight, L. V., \& Wilkinson, C. E. (2007). "User involvement is a sine qua non, almost, in medical education": Learning with rather than just about health and social care service users. Advances in Health Sciences Education, 12(2), 359-390.

Robertson, M., Moir, J., Skelton, J., Dowell, J., \& Cowan, S. (2011). When the business of sharing treatment decisions is not the same as shared decision making: A discourse analysis of decision sharing in general practice. Health, 15(1), 78-95.

Rothstein, M. A. (2010). The Hippocratic bargain and health information technology. The Journal of Law, Medicine \& Ethics, 38(1), 7-13.

Sachs, L., \& Tomson, G. (1992). Medicines and culture-A double perspective on drug utilization in a developing country. Social Science \& Medicine, 34(3), 307-315.

Shaikh, B. T., Kadir, M. M., \& Hatcher, J. (2006). Health care and public health in South Asia. Public Health, 120(2), 142-144.

Sosa-Iudicissa, M., Levett, J., Mandil, S., \& Beales, P. F. (1995). Health, information society and developing countries. Amsterdam: Ios Press.

Stanberry, B. (2001). Legal ethical and risk issues in telemedicine. Computer Methods and Programs in Biomedicine, 64(3), 225-233.

Stenner, K. L., Courtenay, M., \& Carey, N. (2011). Consultations between nurse prescribers and patients with diabetes in primary care: A qualitative study of patient views. International Journal of Nursing Studies, 48(1), 37-46.

Stoopendaal, A., \& Bal, R. (2013). Conferences, tablecloths and cupboards: How to understand the situatedness of quality improvements in long-term care. Social Science \& Medicine, 78, 78-85.

Sujatha, V. (2007). Pluralism in Indian medicine: Medical lore as a genre of medical knowledge. Contributions to Indian Sociology, 41(2), 169-202.

Thornton, P. H. (2004). Markets from culture: Institutional logics and organizational decisions in higher education publishing. Stanford: Stanford University Press.

van Schie, T., \& Seedhouse, D. (1997). The importance of care. Health Care Analysis, 5(4), 283-291.

Walsham, G., Robey, D., \& Sahay, S. (2007). Foreword: Special issue on information systems in developing countries. Management Information Systems Quarterly, 31(2), 317-326.

World Health Organization 2005 (WHA58/2005/REC/1). (2005, May 16-25). Resolution WHA58.28. eHealth. In Fifty-eighth world health assembly. Geneva: WHO. Annex. Resolutions and decisions. Geneva. Available from: apps.who.int/gb/or/e/e_wha58r1.html. Accessed 24 Nov 2013.

Zolfo, M., Bateganya, M. H., Adetifa, I. M., Colebunders, R., \& Lynen, L. (2011). A telemedicine service for HIV/AIDS physicians working in developing countries. Journal of Telemedicine and Telecare, 17(2), 65-70. 